Copyright (C) The Author(s), 2021. Published by Cambridge University Press on behalf of The American Society of International Law.

doi:10.1017/amp.2021.86

\title{
FOREWORD
}

\section{The Promise Of International Law}

The 114th Annual Meeting convened to consider "The Promise of International Law" at a most unpromising moment. The proceedings unfolded in the midst of the worst global pandemic in over a century, which as of this writing has infected over 100 million people and claimed over two million lives. Restrictions on public gatherings made it impossible to hold the meeting in person as planned. However, the leaders of the Society felt it was more important than ever to use the available technology to bring our global community together as we weathered this crisis. We therefore postponed the meeting from April to June, and we used the intervening weeks to redesign the meeting as a two-day virtual conference using a custom-built online platform.

Our goal was to recreate to the greatest possible extent the richness, energy, and vibrancy of an ASIL Annual Meeting. We were able to repurpose and present the more than forty substantive sessions that had been organized by the Annual Meeting Committee, as well as all of the lectures, keynotes, plenary sessions, and governance meetings that would ordinarily have taken place in person. The change to the virtual format with a worldwide audience required us to make substantial changes to the structure and sequence of the meeting. Among other things, we reduced the length of substantive panels to one hour with more frequent breaks to minimize viewer fatigue. With panelists participating from multiple time zones, it was necessary to prerecord some sessions, although as many as possible were presented live. Some evening plenaries were shifted to the morning. As it was not possible to gather the membership for the Annual General Meeting and other portions of the Assembly, we conducted the leadership elections by means of an online ballot sent to all members in good standing, and incorporated the various ceremonial elements of the Assembly, including memorials, honors, and awards, into a live Opening Ceremony and a prerecorded virtual presentation of honors and awards.

Although it was not possible for conferees to meet at receptions, luncheons, and coffee breaks, they were able to enjoy a variety of interactive social, networking, and career development activities designed expressly for our virtual format. These included small group mentoring sessions connecting students and new professionals with leading scholars and practitioners, and "Ask Me Anything" sessions with leaders in the field providing career advice and commentary on international legal issues. Many of the Society's thirty-four Interest Groups took advantage of the opportunity to host meetings and discussions, and we designed a "virtual expo hall" to enable conferees to explore the information and resources presented by our sponsors and exhibitors.

The response of the international law community was overwhelming, and registration was the highest on record. Attendees included members and guests from around the world who had never attended an Annual Meeting before. In addition, conferees who ordinarily would have had to choose among the many concurrent activities were able to view as many sessions as they wished, either as they were happening or on demand. All of the sessions remained available exclusively to conferees for thirty days following the meeting, and then were made accessible to the public as part of the Society's open access video library.

During the two weeks preceding the Annual Meeting, the Society hosted two "preview" sessions, offered free of charge, to introduce both members and non-members to the online meeting 
platform and encourage them to register. Both sessions focused on the impact of the COVID-19 pandemic on international law. The first looked at the challenges for global governance institutions in pursuing a coordinated global response, while the second focused on the disparate impact of the pandemic on marginalized communities.

The formal meeting began on the morning of Thursday, June 25, with an Opening Session featuring remarks by President Catherine Amirfar. She paid tribute to Immediate Past President Sean D. Murphy, who oversaw the planning of the meeting and would have presided had it taken place as originally scheduled. The opening ceremonies included the dedication of a new book award to be known as the Robert E. Dalton Award for Outstanding Contribution in the Field of Foreign Relations Law. The award, created through a generous gift from the Dalton family, honors the life and work of a distinguished U.S. State Department lawyer and longtime member of the Society, and will be presented for the first time at the 2021 Annual Meeting. This was followed by a keynote conversation between Ambassador William J. Burns (Carnegie Endowment for International Peace) and Avril Haines (Columbia University).

Highlights of the first day included the presentation of the 2020 Manley O. Hudson Medal to Professor Rüdiger Wolfrum of the Max Planck Foundation. Following the presentation by President Amirfar, Professor Wolfrum was introduced by Paul S. Reichler of ASIL Law Firm Partner Foley Hoag LLP, which sponsored the event. Professor Wolfrum delivered formal remarks on "The Normativity of Public International Law Reconsidered," after which he participated in a conversation with 2010 Hudson Medal recipient Edith Brown Weiss.

The Thursday sessions concluded with the 22nd annual Grotius Lecture, presented in cooperation with the American University Washington College of Law. The lecture was delivered by James Thuo Gathii of Loyola University Chicago School of Law, on "The Promise of International Law: A Third World View." Fleur Johns of the University of New South Wales Faculty of Law delivered the response.

The Friday sessions began with the presentation of the Goler T. Butcher Medal to Claudio Grossman and the Presentation of the Honorary Member Award to Hina Jilani, followed by a conversation between Professor Grossman and Ms. Jilani, moderated by ASIL's Immediate Past President Sean D. Murphy.

Other programs of note on Friday morning included the Fifth Annual Detlev F. Vagts Roundtable on Transnational Law, convened by Rochelle Dreyfuss of the New York University School of Law, on "Conceptualizing Intellectual Property as a Social Determinant of Health"; and the Eighth Annual Charles N. Brower Lecture on International Dispute Resolution, delivered by Sir Daniel Bethlehem, Q.C., on "The Greening of International Dispute Settlement? Stepping Back a Little."

On Friday afternoon, Judge Elizabeth Odio Benito of the Inter-American Court of Human Rights was the featured speaker at the 27th annual Women in International Law Interest Group program, where she was presented with the 2020 Prominent Woman in International Law Award.

The Closing Plenary featured a roundtable discussion, sponsored by the Asser Institute for International and European Law and the Municipality of The Hague, on "Cities and Other SubNational Entities: What Promise Do They Hold for International Law?” The Annual Meeting concluded with a Closing Ceremony, featuring remarks by President Amirfar, a photomontage of hundreds of Annual Meeting attendees, and a virtual toast featuring the signature cocktail of the 2020 Annual Meeting - the "Charming Betsy" (named for the merchant vessel whose capture gave rise to the Charming Betsy canon) and its alcohol-free counterpart, "The Jane" (the previous name of the schooner).

The success of this first virtual meeting was due to the creativity, hard work, and commitment of many people, including Presidents Sean D. Murphy and Catherine Amirfar; Annual Meeting Co- 
Chairs Joké Babington-Ashaye, Ruchi Gill, and Jarrod Wong, and all of the members of the Annual Meeting Committee; our meeting planner, Eden Capuano, and her team at Voila! Inc.; and most of all, the extraordinary staff of the Society, including our intrepid deputy executive director, Wes Rist, who oversaw the planning from start to finish. All of them spent the better part of a year designing the Annual Meeting, and then devoted another intensive ten weeks to recreating it in virtual form. It was a truly heroic effort by all involved.

Finally, thanks are due to Erin Lovall, the editor of these Proceedings, and to the speakers, sponsors, partners, exhibitors, and registrants who had faith in us and gave us the opportunity to re-envision what an ASIL Annual Meeting could be under the most adverse circumstances.

As the pandemic continues to rage, we are planning yet another virtual Annual Meeting for the spring 2021. We hope you will join us.

MARK DAVID Agrast

Executive Director

February 2021

Washington, DC 